\title{
El principio de justa y proporcional igualdad impositiva
}

Sumario: El presente estudio se refiere al principio constitucional de igualdad tributaria, entendido como de justa y proporcional igualdad impositiva. Para llegar a dicha conclusión, el autor hace un análisis de la construcción del principio en nuestra historia constitucional y desarrolla su actual configuración en la Carta de 1980.

Palabras clave: Igualdad. Tributos. Principios del contribuyente. Justicia tributaria.

Licenciado en

Ciencias Jurídicas

$y$ Sociales.

Profesor Instructor

de Derecho

Constitucional,

Facultad

de Derecho,

Universidad de

Chile. Correo

electrónico

dibaceta@

academiajudicial.cl.

\section{Introducción.}

Se han desarrollado y explicado en estudios anteriores ${ }^{1}$, el contenido, características, manifestaciones y mecanismos de control del principio constitucional de legalidad en materia tributaria, sin embargo, el marco de protección y resguardo de los derechos constitucionales de los contribuyentes, en nuestro sistema, no estaría completo sin una revisión de los principios de igualdad y de no afectación en el ámbito tributario.

El tema del presente estudio se centrará en el principio constitucional de igualdad, que en nuestro concepto y conforme la evolución que ha experimentado en nuestro sistema, se puede denominar como principio de justa y proporcional igualdad impositiva, donde la justicia y la proporcionalidad en el establecimiento de tributos, no constituyen principios autónomos sino que antes y de mejor forma, elementos que estructuran y entregan a la igualdad impositiva los márgenes suficientes que le permiten una operatividad en el ordenamiento jurídico constitucional, respetuosa y coherente con los derechos fundamentales de las personas.

\footnotetext{
MEZA e IBACETA (2007).
} 


\section{Límites Especiales de la Potestad Tributaria.}

La potestad tributaria, además de las disposiciones contenidas en los capítulos I y III de la Constitución, se encuentra limitada desde tres puntos de vista que denominaremos límites formales, límites materiales y límites internacionales. Estos límites constituyen un verdadero resguardo o, si se quiere, una adecuada estructura de garantías de los derechos fundamentales de las personas, desde el punto de vista de sus relaciones con el Estado-Fisco, pues la potestad tributaria deja de concebirse como un arsenal de poderes o facultades discrecionales e ilimitadas, para convertirse en el ejercicio de competencias regladas por parte de los órganos del Estado llamados a regular el ámbito tributario, que en un primer término y tratándose de los elementos primarios del tributo, corresponde al Congreso Nacional, vía aprobación legal.

Con acierto se ha señalado que "Los principios fundamentales del derecho tributario (legalidad, igualdad y tutela jurisdiccional), no constituyen otra cosa más que derivaciones de los principios generales del derecho con las particularidades propias de la materia tributaria, los cuales tiene por fin la protección de los derechos humanos ${ }^{2 "}$.

Hoy en nuestra realidad jurídica, en nuestro Estado democrático de Derecho, no cabe la posibilidad de que un órgano de autoridad del Estado se sustraiga del Imperio del Derecho, por el contrario, debe respetar normas y principios constitucionales, internacionales y legales; por ello se ha señalado con acierto que "todos los derechos fundamentales -no solo los derechos sociales y las obligaciones positivas que imponen al Estado, sino también los derechos de libertad y los correspondientes deberes negativos que limitan sus intervenciones- equivalen a vínculos de sustancia y no de forma, que condicionan la validez sustancia de las normas producidas y expresan, al mismo tiempo, los fines a que está orientado ese moderno artificio que es el Estado constitucional de derecho"'.

En la actualidad los límites de la potestad tributaria del Estado presentan tres márgenes claramente diferenciables.

\section{A) Limites Formales.}

\section{El Principio Constitucional de Legalidad Tributaria.}

Se trata de una garantía en materia tributaria, que debe ser considerada en nuestro sistema jurídico, como la más importante en el orden constitucional y un límite a la 
potestad tributaria ${ }^{4}$. Esta garantía se reduce al brocardo latino "nullum tributo sine lege".

Los particulares cada vez que sientan vulnerados sus derechos por actos arbitrarios o ilegales, de parte de la administración tributaria o del Estado tributario, pueden ejercer las acciones que la ley establezca invocando precisamente esta garantí-límite para que sean protegidos sus intereses.

En cuanto al alcance del principio constitucional de legalidad, el profesor Dino Jarach expresa: “ (....) decir que no debe existir tributo sin ley significa que solo la ley puede establecer la obligación tributaria y, por tanto, solo la ley debe definir cuáles son los supuestos y los elementos de la relación tributaria. Y al decir elementos y supuestos, quiero significar que es la ley la que debe definir los hechos imponibles en su acepción objetiva y también en la esfera subjetiva, o sea, cuáles son los sujetos pasivos de la obligación que va a nacer. Debe ser la ley la que debe establecer el objeto y la cantidad de la prestación, es decir, el criterio con que debe valuarse la materia imponible, para aplicar luego el impuesto en un monto determinado, y, es también la ley la que debe definir este monto" 5 .

Para nosotros, "la ley está llamada a regular los elementos primarios del tributo, que puede entenderse como aquellos elementos necesarios para determinar la existencia, estructura y cuantía de la obligación tributaria, esto es, el hecho gravado, con cada uno de los elementos que lo componen; los sujetos, sean pasivos o activos, y en el caso de los pasivos, no tan solo el propio contribuyente directo sino que también los responsables o los sustitutos; la Base Imponible y la Tasa Impositiva; ello sin perjuicio de la necesidad de que también debe regular los aspectos relativos a la responsabilidad, a la tipificación de las infracciones tributarias y a la imposición de sanciones y establecimiento de limitaciones de los derechos y garantías individuales"6.

Los fundamentos del Principio de Legalidad, según ya lo señalamos en otro estudio ${ }^{7}$, radican en:

i. La protección que debe darse a los particulares en su derecho de propiedad;

ii. El principio de autoimposición, lo que implica la idea de que los contribuyentes solo paguen aquellos tributos que han consentido en su establecimiento y que descansa en la exigencia propia del Estado democrático de Derecho, de que sean los representantes del pueblo quienes tengan directa intervención en aquellos actos del poder político tributario, tendientes a obtener del patrimonio de los

\footnotetext{
Sobre el particular en la reciente jurisprudencia del Tribunal Constitucional: Álvarez de la Rivera Schmidt con Servicio de Impuestos Internos (2007), Sociedad de Deportes Palestina S.A. con Servicio de Impuestos Internos (2007), Sociedad Anónima de Deportes Manquehue con Servicio de Impuestos Internos (2007), Estadio Español S.A. con Servicio de Impuestos Internos (2007), Estadio Croata S.A. con Servicio de Impuestos Internos (2009), Compañia Generales de Seguros con Superintendencia de Valores y Seguros (2009). JARACH (1980) p. 80.

MEZA e IBACETA (2007) p. 219.

MEZA e IBACETA (2007) pp. 185 - 188 y con anterioridad MEZA e IBACETA (2004) pp. 178 - 180.
} 
particulares los recursos necesarios para el cumplimiento de los fines de bien común del Estado;

iii. El principio democrático de separación de funciones ${ }^{8}$, de carácter esencial en el actual régimen democrático, impidiendo en su virtud la acumulación excesiva de los poderes; $y$

iv. El principio de igualdad ante la ley tributaria.

\section{B) Limites Materiales.}

En el sistema jurídico nacional la potestad tributaria encuentra determinados límites materiales que dicen relación con el resguardo de los derechos y garantías de las personas. Estos límites materiales constituyen presupuestos necesarios en un Estado Democrático y Constitucional de Derecho, pues le dan plena vigencia y limitan el actuar de la administración tributaria.

1) Principio de Justa y Proporcional Igualdad Tributaria.

Sobre este principio, nos adentraremos con mayor detención más adelante.

\section{2) Principio de No Afectación de los Tributos a Objetivos Específicos y Determinados.}

El constituyente no definió el contenido de lo que debe entenderse por no afectación. El Diccionario de la RAE señala que afectación importa: "Acción de afectar", a su turno afectar es: "Destinar una suma o un bien a un gasto o finalidad determinados", o, "Destinar algo a un uso o servicio público"10.

Con lo anterior podemos señalar que el Principio de No Afectación Tributaria consiste en que ninguna de las sumas que ingresen a las arcas fiscales podrán ser destinadas a un gasto o finalidad determinada.

Este principio encuentra sus fundamentos en tres circunstancias:

i. Conceder libertad al poder ejecutivo para asignar los recursos;

ii. El principio de universalidad de los ingresos públicos, en cuya virtud todos y cada uno de los ingresos deben ser conducidos al fondo común del Fisco; y 
iii. Evitar el ejercicio de presiones sobre el cuerpo del Congreso Nacional, orientadas a conseguir que ciertos tributos sean destinados a áreas especiales de inversión o gasto fiscal.

Sin embargo, este principio reconoce, en nuestro sistema constitucional, las siguientes excepciones, sean ellas de carácter permanente o transitorio.

\section{Entre las excepciones permanentes encontramos:}

a. Tributos afectados a fines propios de la Defensa Nacional, según lo dispone el artículo 19 número 20, inciso $4^{\circ}$ de la Constitución. Esto se justifica en cierta forma por razones de urgencia.

b. Tributos que gravan actividades o bienes que tengan una clara identificación regional o local, para que puedan ser aplicados, dentro de los marcos que la misma ley señale, por las autoridades regionales o comunales para el financiamiento de obras de desarrollo, todo ello de conformidad a lo preceptuado por la segunda parte del inciso $4^{\circ}$ del número 20 del artículo 19 del texto constitucional. Puede considerarse a esta como una excepción en la cual se manifiesta algún grado de descentralización en la toma de decisiones por parte de la autoridad pública.

Tratándose de las excepciones transitorias, nuestro sistema tributario - constitucional sólo reconoce una alternativa: Disposiciones legales vigentes al momento de entrar a regir la Constitución que establezcan tributos de afectación, mientras no sean expresamente derogados, norma establecida en la séptima disposición transitoria de la Constitución ${ }^{11}$.

11 Con relación a esta norma el Tribunal Constitucional, con fecha 06 de diciembre de 1994, en Rol № 203, fijó un criterio de interpretación de la carta fundamental en orden a que, ese órgano no puede pronunciarse sobre disposiciones inconstitucionales cuya vigencia es anterior a la entrada en vigor de la Constitución, al señalar que: "50. Que, sobre el particular y de acuerdo con el artículo 82 de la Constitución Política, es menester precisar que el Tribunal solo tiene competencia para pronunciarse sobre la modificación introducida al artículo 24, inciso segundo, del Decreto Ley $N^{\circ} 3.063$, de 1979, que consiste en el cambio de 1.000 unidades tributarias mensuales por 4.000 unidades tributarias mensuales para los efectos de fijar la patente municipal. Si bien el resto de la disposición le sirve de sustento a la aplicación del límite máximo y le permite al intérprete analizar la posible discrepancia de la modificación con el texto constitucional, las atribuciones de éste le impiden pronunciarse sobre el contenido que no ha sido modificado, por tratarse de ley vigente, ya que de la sola lectura de la Carta Fundamental resulta evidente que el control de constitucionalidad que ejerce el Tribunal Constitucional, es solamente preventivo y no a posteriori". Cabe señalar además que el voto de mayoría estimó que no es contraria a la Constitución una norma legal que reformando el Decreto Ley 3.063 sobre rentas municipales, aumenta de 1.000 a 4.000 Unidades Tributarias mensuales el máximo de capital propio sobre el que se calcula el valor de la respectiva patente municipal. No pueden considerarse reproches de inconstitucionalidad que afecten al texto vigente por carecer para ello de competencia el Tribunal. Además seńaló que no es desproporcionado o injusto el aumento introducido por la reforma legal, como tampoco contraría dicha reforma la prohibición del artículo 19 número 2 de la Carta porque el principio de igualdad jurídica significa que las normas jurídicas deben ser iguales para todas las personas que se encuentren en las mismas circunstancias y consecuencialmente diversas para aquellas que se encuentren en situaciones diferentes. Por otra parte, rescato el voto disidente del Ministro Sr. Ricardo García, que luego de hacer referencia a los supuestos que implican no afectación, y deteniéndose con mayor detalle en la $7^{\text {a }}$ disposición transitoria, señala que: "QUINTO: La segunda situación que el constituyente previó fue la relativa a normas que habian establecido tributos de afectación, que se encontraban vigentes a la fecha de la nueva Carta Fundamental y cuya aplicación incidia en las actividades nacionales, de manera que su pérdida de vigencia podría ocasionar trastornos que era conveniente evitar. Para atender a esta situación, el constituyente incorporó a la Constitución Política de 1980 el artículo $7^{\circ}$ transitorio que estableció: "Sin perjuicio de lo dispuesto en el inciso tercero del número $20^{\circ}$ del artículo 
Es preciso señalar, que existe una diferencia entre lo que es la justificación de un tributo y su predestinación. En el primer caso, cuando estamos frente a un tributo que es considerado fuente de financiamiento de un gasto, por mucho que se señale la causa que da origen al establecimiento del tributo o el efecto que se busca provocar con él, la recaudación del mismo ingresa de todos modos al erario nacional y los excedentes no son devueltos. En la segunda circunstancia antes señalada, tratándose de la afectación de un tributo a un fin, el tributo guarda directa y estrecha relación con esa finalidad; no ingresa previamente al patrimonio de la nación.

Además debemos recordar lo señalado en el inciso $4^{\circ}$ del artículo 67 del texto constitucional en orden a que "no podrá el Congreso aprobar ningún nuevo gasto con cargo a los fondos de la Nación sin que se indiquen, al mismo tiempo, las fuentes de recurso necesarios para atender dicho gasto", de ahí entonces que la precisión conceptual tome mayor importancia, pues una cosa es contemplar un tributo como fuente de financiamiento de un determinado gasto o inversión pública -término escasamente utilizado en nuestra literatura jurídica-, y otra cosa muy distinta es "condicionar un gasto a una recaudación tributaria específica, directa y jurídicamente afectada a un destino vinculado a ese gasto ${ }^{12}$ ".

\section{C) Limites Internacionales.}

Hoy en día no solo puede hablarse de la existencia de límites de carácter interno, como son los límites formales o sustanciales, pues producto del desarrollo de las relaciones comerciales entre los diversos Estados, se hace cada vez más frecuente y toman una mayor importancia los tratados internacionales, los acuerdos de complementación económica o los convenios de asistencia mutua económica.

Basta con recordar, entre los más relevantes, los tratados de libre comercio existentes con Canadá y México, como asimismo los Tratados y Acuerdos Comerciales logrados con la Comunidad Económica Europea, Corea del Sur o Estados Unidos.

Cuando se producen o configuran relaciones recíprocas y estrechas entre los poderes tributarios de los Estados, lo que se hace es prevenir dos tipos de problemas: primero,

19, mantendrán su vigencia las disposiciones legales que hayan establecido tributos de afectación a un destino determinado, mientras no sean expresamente derogadas."; SEXTO: Dicha disposición transitoria constituyó un llamado al legislador a regularizar las situaciones derivadas de aquellas normas legales cuya vigencia resultaba excepcionalmente necesario mantener, invitándolo a legislar de conformidad con las normas constitucionales permanentes y, en especial, con sujeción a la plenitud de lo establecido en el numeral 20 del artículo 19 de la Carta Fundamental; SÉPTIMO: Como norma de carácter transitoria que es, corresponde interpretar dicha disposición séptima en su estricto sentido, sin analogias ni extensiones, a fin de que su aplicación se circunscriba exacta y limitadamente al objetivo que la ha motivado. Por lo mismo, resulta ineludible interpretar su alcance en orden a permitir que aquellas leyes de afectación que se las ha debido dejar vigentes, sólo subsistan "mientras no sean expresamente derogadas", no resultando por ello procedente, hacerlas objeto de modificaciones que alteren el texto con que se las permitió subsistir, el cual, obviamente, ha quedado ligado a la prórroga constitucional de su vigencia".

12 EVANS DE LA CUADRA y EVANS ESPIÑEIRA (1997) p. 101. 
establecer normas y reglas del juego claras respecto de la denominada doble tributación internacional; y, en segundo lugar, evitar la evasión tributaria internacional.

La solución de estas problemáticas puede realizarse ya sea mediante una regulación específica y detallada del derecho interno que prevea todas las hipótesis posibles o a través de mecanismos de coordinación con otros Estados, lo cual se logra a través de Tratados Internacionales ${ }^{13}$.

Cuando se ha regulado el problema de relación entre dos o más poderes tributarios a través de los tratados internacionales, ello se puede proyectar sobre tres planos:

i. Atribuyendo a los Estados partes la potestad de establecer recursos tributarios propios;

ii. Imponiendo determinados límites, prohibiciones y controles al poder impositivo de los Estados miembros; $y$

iii. Permitiendo una actividad de armonización entre los diversos ordenamientos constitucionales tributarios de los Estados miembros.

Lamentablemente en nuestro país la interpretación que se ha hecho de los límites internacionales a la potestad tributaria es, por decirlo de alguna manera, precaria, pues se desconocen las normas tributarias internacionales o se da a ellas un significado que no se corresponde con su texto y menos aún con su espíritu.

\section{El Principio Constitucional de Justa y Proporcional Igualdad Impositiva en el Constitucionalismo Chileno.}

Antes de analizar y determinar que el principio de igualdad tributaria no mantiene la misma estructura tradicionalmente estudiada y que estamos ante un principio que ha mutado y desarrollado una nueva fisonomía, que lo llevan a definirse como de Justa y Proporcional Igualdad Tributaria, menester es revisar brevemente cómo se ha manifestado en los textos constitucionales chilenos, antecedente de vital importancia, para entender bajo qué principios y concepciones se construyó el principio constitucional del contribuyente en análisis.

\footnotetext{
Se ha definido a los tratados internacionales como "(....) un acuerdo internacional celebrado generalmente entre Estados, regidos por el Derecho internacional y destinado a producir efectos juridicos”, BENADAVA (1993) p. 65. A su turno la Convención de Viena sobre Derecho de los Tratados lo ha definido, para los fines de la Convención, como "un acuerdo internacional celebrado por escrito entre Estados y regido por el derecho internacional, ya conste en un instrumento único o en dos o más instrumentos conexos y cualquiera que sea su denominación particular." Nosotros agregaremos que, desde el ROL TC 325 Corte Penal Internacional (2002); dichos tratados deben en todo caso respetar el contenido de las disposiciones constitucionales vigentes en el ordenamiento jurídico nacional, so pena de tenerse por inconstitucional el contenido de dicho tratado.
} 


\section{A) Antecedentes Constitucionales sobre el Principio Constitucional de Legalidad.}

1) Primer Período (1811 - 1828).

Del análisis de los diversos cuerpos constitucionales de esta época, observamos que la referencia al principio de igualdad impositiva es precaria: ninguna de sus normas se refiere explícitamente a este ámbito, sin embargo, se encuentran algunas aproximaciones.

a. En primer término la Constitución del año 1818, en su Título Primero, sobre los Derechos y Deberes del hombre en Sociedad, Capítulo II (deberes del hombre en sociedad), artículo $2^{\circ}$, establece que, "Debe igualmente ayudar con alguna porción de sus bienes para los gastos ordinarios del Estado; y en sus necesidades extraordinarias y peligros, debe sacrificar lo más estimable por conservar su existencia y libertad ${ }^{14 ”}$. Esta norma, más que establecer una igualdad en la imposición, constituyó un intento de regular la generalidad en la contribución de las personas a los gastos del Estado.

b. La Constitución del año 1822, conjuntamente con el establecimiento de la legalidad tributaria, reforzó y estableció por primera vez en un texto constitucional chileno, el principio de igualdad tributaria según se desprende de lo expresamente señalado en el artículo $6^{\circ}$ al establecer que "Todos los chilenos son iguales anta la ley, sin distinción de rango ni privilegio ${ }^{15}$; norma que se relaciona con lo dispuesto en el artículo $8^{\circ}$ que dice "Todos deben contribuir para los gastos del Estado en proporción de sus haberes ${ }^{16}$ ". Esta disposición está dentro del ámbito tributario ya que se refiere a la contribución que deben realizar todos los individuos para financiar las necesidades del Estado. Por otra parte, resulta de enorme importancia la conjunción de estas normas, ya que aquí se manifiesta, aunque no expresamente, la justicia tributaria, primero al establecer que "todos", o sea, todos los habitantes de la República, sin distinción alguna, deben contribuir para los gastos del Estado; sin embargo, esto no quiere decir que el aporte que realicen todas las personas deba tener una igualdad numérica ya que la contribución que se establece en la ley es "en proporción de sus haberes", de modo que cada individuo ayudará a financiar estos gastos del Estado dependiendo de su capacidad contributiva, de ahí entonces que podamos señalar que estamos aquí en presencia del Principio de Igualdad pero no ante la ley sino que más bien en una "igualdad por la ley".

Ahora toda esta estructura normativa del sistema constitucional-tributario chocaba con dos normas, que interpretadas conjuntamente, dan la impresión de que la imposición de tributos era excepcionalísima. De acuerdo con lo dispuesto en al

\footnotetext{
VALENCIA (1986) pp. $67-68$.

VALENCIA (1986) p. 83.

VALENCIA (1986) p. 84.
} 
artículo 221, "Todo ciudadano tiene la libre disposición de sus bienes, rentas, trabajo e industria; así es que no se podrán poner impuestos sino en los casos muy urgentes, para salvar con la Patria las vidas y el resto de la fortuna de cada uno ${ }^{17}$ ". A su turno el artículo 222 de la Ley Fundamental señalaba que "la industria no conocerá trabas, y se irán aboliendo los impuestos sobre sus productos ${ }^{18}{ }^{\prime \prime}$. Si observamos detenidamente lo establecido en este conjunto normativo, podemos concluir que la imposición tributaria solo procedía en muy determinados casos, aun más, en el ámbito industrial la idea era de abolir los impuestos.

Sin embargo, las normas anteriores están en contradicción total con la norma del artículo $8^{\circ}$, pues solo a través de la imposición de contribuciones o impuestos era posible solventar los gastos del Estado, de modo que una contradicción tan importante como la antes mencionada, nos parece a lo menos, poco coherente con un sistema normativo sistemático y armónico.

c. Por último, en este período, cabe hacer referencia a la Constitución del año 1823. En su aspecto genérico la igualdad ya se encontraba establecida en el artículo $7^{\circ}$, al señalar que "Todo chileno es igual delante de la ley; puede ser llamado a los empleos con las condiciones que ésta exige; todos contribuyen a las cargas del Estado en proporción de sus haberes; todos son sus defensores ${ }^{19}$ ". En cuanto a la igualdad en el reparto de los tributos, en la Constitución Política de 1822 ya se había dictado una norma similar que establecía que todos debían contribuir para los gastos del Estado en proporción de sus haberes; es claro que esta es una norma que se refiere al principio de igualdad en el reparto de los tributos, a diferencia de lo que expresa el autor Juan Eduardo Figueroa ${ }^{20}$. Nosotros pensamos que esta Constitución no fue la primera en que se hace referencia a este principio, lo cual quedó enteramente demostrado al revisar las normas de la Constitución Política de $1822 .{ }^{21}$

Esta norma no solo regula de forma bastante clara la circunstancia de que todas las personas debían contribuir a las cargas del Estado, sino que también, y en estrecha relación con aquella generalidad, se establecía que dicha contribución debía realizarse de acuerdo a los haberes de quienes estén obligados a dichos gastos. Finalmente, cabe agregar que esta norma regula, antes de la situación impositiva, el principio de igualdad ante la ley.

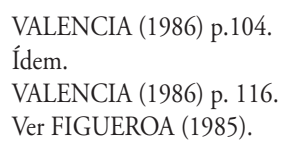


2) Segundo Período (1833 - 1925).

\section{a) Constitución Política de 1833 .}

En el texto de esta Constitución, el artículo 12, al interior del Capítulo V, sobre "El Derecho Público Chileno", regulaba los derechos fundamentales, al decir que "La Constitución asegura a todos los habitantes de la República”.

El numeral $1^{\circ}$ del artículo 12 del texto constitucional de 1833 señalaba que: "La constitución asegura a todos los habitantes de la República: $1^{\circ}$. La igualdad ante la lei. En Chile no hay clase privilegiada”. A su turno el numeral $3^{\circ}$ del artículo en comento establecía que: "La Constitución asegura a todos los habitantes de la República: 3º La igual repartición de los impuestos i contribuciones a proporción de los haberes, i la igual repartición de las demás cargas públicas”. Estos artículos establecían el estatuto de la igualdad constitucional tributaria, donde lo característico era que dicha igualdad dependía de la proporción de los haberes, estableciéndose de esta forma las primeras referencias a la proporcionalidad del tributo, que según señalamos con anterioridad, tiene como fundamento la equidad y justicia en el tratamiento tributario que deben dar el Estado y sus órganos a los particulares.

Esta norma, por primera vez en nuestra historia constitucional, establece expresa y categóricamente el principio de igualdad en materia tributaria, fijando como elemento diferenciador de cualquier otra igualdad, la circunstancia de que en este ámbito se aplicaría tomando en consideración la proporción de los haberes. En opinión de la doctrina ${ }^{22}$, esta figura se identificaba con la justicia tributaria y el término haberes debía entenderse como "facultades", no guardando relación con su tenor literal.

Cabe señalar, que en el ámbito constitucional solo aparece el principio de igualdad impositiva, pues la generalidad y la proporcionalidad, solo vienen a darle un alcance específico y determinado a esta igualdad.

\section{b) Constitución Política de 1925 .}

Este cuerpo constitucional estableció normas tributarias bastante similares a lo preceptuado por el texto del ańo 1833, tratándose del principio de igualdad impositiva.

Así el artículo 10 número 1, inserto en el Capítulo III, sobre "Garantías Constitucionales", seńalaba que: "La Constitución asegura a todos los habitantes de la República: $1^{\circ}$. La igualdad ante la lei. En Chile no hai clase privilegiada", estableciendo el principio constitucional de igualdad ante la ley. Por su parte el numeral 9o establecía, como proyección de lo preceptuado en el numeral 1º, que: "La Constitución asegura a todos los habitantes de la República: 9º La igual repartición de los impuestos y 
contribuciones, en proporción de los haberes o en la progresión o forma que fije la lei; y la igual repartición de las cargas públicas”.

Podemos apreciar, que únicamente se hace referencia, en lo que nos importa, a la Igualdad Tributaria, erigiéndose la generalidad (todos) y la proporcionalidad como elementos que le dan cierta fisonomía al principio; más aún, y en esto comparto lo señalado por el profesor Alejandro Silva Bascuñán, "el principio de la igualdad de los habitantes ante el impuesto no está establecido en forma absoluta, como lo consagró respecto de la igualdad ante la ley" ${ }^{23}$. Correspondía entonces al legislador precisar los diversos alcances de la igualdad, como ya lo adelantó el constituyente, al referirse a la progresión de los haberes, de la proporción o la forma en cómo se debía materializar la igualdad impositiva.

Para cerrar este tema, observamos que en la historia constitucional chilena, hasta el texto del año 1925, solo aparecían como principios inspiradores del sistema tributario constitucional chileno, la Legalidad y la Igualdad, no existiendo referencias de ningún tipo a la justicia, la capacidad contributiva, la no confiscatoriedad o la proporcionalidad ${ }^{24}$ como verdaderos principios inspiradores de un sistema de garantías de las personas.

\section{B) Configuración del Principio Constitucional de Igualdad Impositiva en la Constitución Política de 1980.}

\section{1) Aspectos Generales.}

Conjuntamente con el principio constitucional de legalidad tributaria, de profunda raigambre democrática, el principio de igualdad constituye un claro límite material o sustancial al poder tributario estatal y, por consiguiente, las reglas que en él se inspiran se orientan decididamente a poner coto a la arbitrariedad y a la desmesura. No se trata de establecer una igualdad aritmética o, como seńala un autor, "no se refiere a una

\footnotetext{
SILVA (1963) p. 319.

De gran ayuda, en orden a corroborar lo señalado, es lo planteado por el profesor Silva Bascuñán, quien entiende que la proporción o la proporcionalidad constituyen herramientas tendientes a hacer efectiva la justicia en la imposición de tributos y de ahí, asegurar la verdadera igualdad impositiva. Gráfico es al señalar que “(...) fue una pauta que se siguió constantemente en la época de formación del constitucionalismo clásico, asegurar la igualdad ante el impuesto sobre la base de una misma proporción o porcentaje del bien gravado mantenido invariable cualquiera que sea el monto de éste. Son los impuestos estrictamente proporcionales", y continúa, "sin embargo, más adelante la ciencia tributaria, en su avance, comprende que, sobre tal cimiento, no se garantiza la justicia verdadera y práctica frente al impuesto, y se propagan nuevas formas tributarias por las que se fijan porciones o porcentajes diversos según el monto de valor gravado, buscando una semejanza del sacrificio efectivo de los diversos contribuyentes"; SILVA (1963) p. 320.
} 
igualdad en términos numéricos, sino que se trata de asegurar el mismo tratamiento tributario a quienes se encuentran en análogas situaciones" 25 .

La tributación tiene que reparar en las diferencias de renta y riqueza existentes en la sociedad, de modo que el deber fiscal, expresión de la solidaridad social, tome en cuenta la capacidad contributiva de los sujetos y grupos y, conforme a ella, determine la carga fiscal, la que ha de asignar con criterios de progresividad, a fin de alcanzar grados cada vez mayores de redistribución del ingreso nacional.

La igualdad impone, y por ello podemos sin miedos hablar de elementos o subprincipios de la igualdad tributaria o impositiva, la necesidad de acatar como regla tributaria básica la generalidad del tributo. Si al margen de los contribuyentes se coloca a aquellas personas que carecen de capacidad contributiva, todos los demás ciudadanos, según su poder económico y en los términos de la ley, quedan sujetos al mismo deber de concurrir al levantamiento de las cargas públicas. El privilegio en la ley y en la aplicación de la ley, resulta definitivamente proscrito, pues el poder tributario se fundamenta, además, en la justicia, la proporcionalidad y la no confiscatoriedad de los tributos.

\section{2) Consagración en el texto Constitucional.}

El principio de igualdad tributaria constituye una manifestación o reiteración del principio de igualdad constitucional ante la ley y, más aún, del principio General de la Igualdad, específicamente referida al ámbito de los tributos y de las demás cargas públicas, según lo establece el número 20 del artículo 19 de la Constitución. Con esto, en términos generales “ (....) quedan excluidas las discriminaciones, pero son admitidas y propiciadas las diferencias justas o razonables ${ }^{26 ”}$.

En nuestro sistema constitucional la Igualdad Tributaria se establece, en su artículo 19 en los siguientes términos: "La Constitución asegura a todas las personas: $20^{\circ}$. La igual repartición de los tributos en proporción a las rentas o en la progresión o forma que fije la ley, y la igual repartición de las cargas públicas". Desde ya aparece claramente que "en nuestra Carta se reconoce como titular de derechos constitucionales, en una primera aproximación, a toda persona, según el encabezado del artículo $19 \mathrm{CPR}$, en relación con el artículo $1^{\circ}$ inc. I." ${ }^{27}$

Se dice que hay dos modalidades del principio de igualdad:

a. Igualdad por la ley. Ésta, advirtiendo que existen desigualdades, las corrige por medio de sus preceptos. Para conseguir este propósito, establece diferencias entre las personas. O sea, la legislación no parte sobre la base de que todos son iguales;

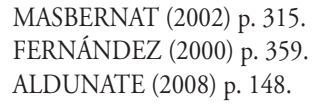


por el contrario, de que hay diferencias y que, por lo mismo, en concordancia con el principio de igualdad, ella debe subsanarlas.

b. Igualdad ante la ley. Bajo esta modalidad del principio, la ley sí parte sobre la base de que todas las personas son iguales. En consecuencia, la ley no puede establecer discriminaciones arbitrarias alterando esta igualdad.

El primero aparece directamente asociado al respeto de los Derechos Humanos de la primera generación, fundamentalmente el de libertad y el de propiedad; mientras que el segundo guarda una directa relación con los derechos económicos y sociales o de segunda generación.

El artículo 19 número 2 de la Constitución Política ${ }^{28}$ contiene un principio de igualdad general, que pone a todos en una posición de igualdad ante la ley, mientras el artículo 19 número 20 del texto Constitucional, en cambio, no parte sobre la base de que todos son iguales; por el contrario, hace distingo en lo que dice relación con la capacidad contributiva de los individuos. O sea, en este último caso la igualdad se concreta cuando la ley tributaria toma en consideración las diversas capacidades contributivas o económicas, si se quiere, de los individuos y, de acuerdo con ellas, establece tratos también distintos o diferenciados.

Lo dicho es en buena medida posible debido a que los números 2 y $22^{29}$ del artículo 19 permiten establecer diferencias, con tal que éstas no sean arbitrarias.

Nuestros tribunales lo vinculan de manera muy estrecha con el principio de legalidad, porque estiman que la igualdad se obtiene mediante la progresión, proporción y forma de los tributos que establece la ley. En otras palabras, antes de evaluar si el tributo establece una diferencia no permitida por la Constitución, debe determinarse si esta diferenciación ha sido o no fijada por ley. Si la respuesta es positiva, se considera que el principio de igualdad ha sido respetado; ello resulta relevante, pues de esa forma se entienden a la proporcionalidad y a la progresividad como elementos de la igualdad tributaria.

En verdad, el principio de igualdad supone una comparación de la categoría afectada con otras que si bien pueden no realizar actividades iguales, tienen, sin embargo, una capacidad contributiva similar.

28 Dice el artículo 19 número $2^{\circ}$ de la Constitución Política que: "La Constitución asegura a todas las personas: 2 La igualdad ante la ley. En Chile no hay persona ni grupo privilegiado. En Chile no hay esclavos y el que pise su territorio queda libre. Hombres y mujeres son iguales ante la ley". Finaliza en inciso $2^{\circ}$ de esta norma señalando que, "Ni la ley ni autoridad alguna podrán establecer diferencias arbitrarias".

29 Reza el artículo 19 número 22 de la Constitución Política: "La Constitución asegura a todas las personas: 22. La no discriminación arbitraria en el trato que deben dar el Estado y sus organismos en materia económica". Termina el inciso $2^{\circ}$, estableciendo que: "Solo en virtud de una ley, y siempre que no signifique tal discriminación, se podrán autorizar determinados beneficios directos o indirectos a favor de algún sector, actividad o zona geográfica, o establecer gravámenes especiales que afecten a uno u otras. En el caso de las franquicias o beneficios indirectos, la estimación del costo de éstos deberá incluirse anualmente en la Ley de Presupuestos". 
Ingresando en la materia tributaria y siguiendo las enseñanzas del gran maestro uruguayo Ramón Valdés Costa, esta acepción del concepto de igualdad en la ley, admite ser analizada en sus dos aspectos, "la igualdad jurídica" y "la igualdad económica"30. La primera, la igualdad jurídica, hace referencia al igual tratamiento de la ley para todas las personas y a la no discriminación por razones intrínsecas con su condición humana, tal como surge del artículo 2 de la Declaración Universal de los Derechos Humanos al declarar que los derechos y libertades rigen sin distinción alguna de razas, color, sexo, idioma, religión, opinión, política o de cualquier otra naturaleza, origen nacional o social, posición económica, nacimiento o cualquier otra condición”. Asimismo la Convención Americana de Derechos Humanos o "Pacto de San José de Costa Rica” establece en su artículo $1^{\circ}$ que los derechos y libertades deben ser respetados por los Estados parte, "sin discriminación alguna por motivos de raza, color, sexo, idioma, religión, opiniones políticas o de cualquier otra índole, origen nacional o social, posición económica, nacimiento o cualquier otra condición social”. Resulta interesante el presente tratamiento, pues se asocian al principio de igualdad tributaria, los elementos de las normas internacionales, con lo cual se refuerza la idea de que la potestad tributaria tiene límites internacionales.

En el ámbito tributario, este aspecto del derecho de igualdad, se traduce en la ilegitimidad de la creación de tributos que tengan por finalidad gravar en forma exclusiva a personas que profesen una determinada religión o ideología política o tengan una determinada raza, nacionalidad o sexo. Establecer un tributo con las características reseñadas sería absolutamente ilegítimo y, desde luego, inconstitucional, en tanto tendría una finalidad exclusivamente discriminatoria.

En cuanto a la "igualdad económica", la cual se encuentra directamente vinculada con la materia tributaria, en tanto hace referencia a la igualdad ante las cargas públicas, debe entenderse por dicha igualdad al igual tratamiento tributario que corresponderá conferir a aquellas personas que posean similar capacidad contributiva, procurando así, el logro de la justicia tributaria a través de la neutralidad fiscal. Esta estrecha vinculación entre la igualdad ante las cargas públicas y la capacidad contributiva, permite concluir que la capacidad contributiva es una derivación directa del principio de igualdad y de ahí en más, constituye un elemento o subprincipio, de carácter implícito, que se encuentra en estrecha armonía con él.

El concepto de "igualdad económica o material" es propio del denominado Estado Social de Derecho de fines del siglo XIX, consolidado en el siglo XX, en virtud del cual, la igualdad es un logro a alcanzar y que el Estado debe intervenir en la vida social y económica a los efectos de eliminar las profundas situaciones de desigualdad que existan.

La igualdad real ante la ley, en el ámbito tributario, solo puede tener lugar a condición de que los hechos bajo examen correspondan material y jurídicamente a los elementos 
primarios de la obligación tributaria, a saber, el hecho generador, los sujetos, sean pasivos o activos, la tasa impositiva y la base imponible. Por lo mismo, el sentido de igualdad en sede fiscal debe reconocerse tanto desde el punto de vista de la regla general que compele al ciudadano a tributar, como desde la óptica de las excepciones que con riguroso y restrictivo acento establece algunos beneficios asociados a determinados hechos económicos, lo que es sumamente relevante y vuelve a relacionar a la igualdad impositiva con la capacidad contributiva del sujeto pasivo tributario.

En síntesis, sin perjuicio de los elementos neutros, el derecho a la igualdad debe asumirse tanto en lo favorable como en lo desfavorable a los extremos de la obligación tributaria, habida consideración de una materialidad dada en cifras económicas, dentro de un espacio y tiempo determinados, y claro, en orden a la justa realización del principio de igualdad frente a las cargas públicas, lo que sin duda alguna, atiende a la cabal realización de los lineamientos de bien común, igualdad y respeto por los derechos fundamentales de la persona, expresamente establecidos en la Constitución y que constituyen bases fundamentales del ordenamiento constitucional.

\section{3) Elementos del Principio Constitucional de Igualdad Impositiva.}

A diferencia de lo que tradicionalmente se ha seńalado en esta materia, y considerando los valiosos antecedentes del establecimiento de la igualdad impositiva en nuestro constitucionalismo, podemos concluir que este principio, en nuestro sistema, y especialmente a partir de la Constitución de 1980, y a diferencia de las legislaciones comparadas $^{31}$, constituye una estructura compleja, en la cual pueden distinguirse elementos o subprincipios explícitos en el texto de la Carta Fundamental y otros implícitos, y que si bien no se establecieron por el constituyente, éste los tuvo en consideración, tratándose de elementos sin los cuales el principio de igualdad impositiva no cumple sus objetivos, en primer término, de garantía de los derechos fundamentales de las personas e instrumento de obtención del bien común, y en segundo lugar no produce los efectos deseados en el ámbito de las políticas fiscales.

A continuación nos detendremos en aquellos elementos.

31 En otros sistemas, los que en mi concepto constituyen elementos o Subprincipios del Principio Constitucional de Igualdad Tributaria, han sido configurados como verdaderos principios con caracteres y contenido propios, v.gr., el artículo 31 de la Constitución Española establece que, "Artículo 31. 1. Todos contribuirán al sostenimiento de los gastos públicos de acuerdo con su capacidad económica mediante un sistema tributario justo inspirado en los principios de igualdad y progresividad que, en ningún caso, tendrá alcance confiscatorio. 2. El gasto público realizará una asignación equitativa de los recursos públicos, y su programación y ejecución responderán a los criterios de eficiencia y economía. 3. Sólo podrán establecerse prestaciones personales o patrimoniales de carácter público con arreglo a la ley". Se puede observar claramente en el punto 1, que la Constitución Española puso de manifiesto, y ello se complementa con la Ley de Derechos y Garantías Constitucionales de los Contribuyentes, de 26 de febrero de 1998, que el sistema tributario español tendría como bases fundamentales: La Generalidad, La Capacidad Económica, La Justicia, La Igualdad, La Progresividad y La No Confiscatoriedad, circunstancia que de solo examinar el número 20 del artículo 19 de nuestra Carta Fundamental no se presenta. 


\section{A) Elementos o Subprincipios Explícitos.}

\section{1) Subprincipio de Justicia Impositiva o Tributaria.}

Este elemento se encuentra consagrado, explícitamente, en el inciso $2^{\circ}$ del número 20 del artículo 19 de la Constitución en los siguientes términos: "En ningún caso la ley podrá establecer tributos (....) injustos”.

Hay que reparar que en el texto constitucional antes transcrito se establecen dos elementos, el ya señalado de justicia impositiva, y el de proporcionalidad impositiva, sobre el que nos referiremos más adelante, lo que se obtiene al observar que la Constitución habla de "... desproporcionados o injustos".

El vocablo injusto debe entenderse como: "No justo o equitativo"32, a su turno, justo es sinónimo de "Arreglado a justicia y razón”, y justicia es: "Una de las cuatro virtudes cardinales, que inclina a dar a cada uno lo que le corresponde o pertenece" ${ }^{\text {. }}$. De lo anterior podemos seńalar que un tributo será injusto cuando no sea justo o equitativo, esto es, cuando no dé a cada uno lo que le corresponde o pertenece; ello llevado al tema tributario, que signifique una perturbación o afección a los derechos constitucionales, como asimismo que no signifique una perturbación en su capacidad contributiva, de ahí la íntima relación con este elemento implícito que más adelante describiremos.

En cuanto a lo que debe entenderse como justicia tributaria rescatamos lo señalado por el profesor Fernández González quien, tratándolo como principio y a contrario sensu, señala que “ (....) la injusticia tributaria, entonces, importa la transgresión de principios y normas que pueden calificarse como cualitativos, de frente a los elementos cuantitativos que se protegen mediante la proporcionalidad ${ }^{34}$.

Efectivamente lo que busca el elemento o subprincipio en estudio es que los elementos cualitativos, esto es, los elementos o caracteres propios que determinan cada uno de los tributos y que los distinguen de otros institutos, sean tributarios en particular o jurídicos en general, se impongan por el legislador con estricto respeto a los derechos constitucionales.

También resulta interesante lo prescrito por los profesores Evans de la Cuadra y Evans Espiñeira, pues refuerzan lo antes mencionado, cuando señalan que "(....) es necesario interpretar la justicia tributaria en el sentido que los impuestos, cualquiera que sea su naturaleza, sean equitativos, en términos tales que por medio de ellos no se altere la esencia o núcleo fundamental de otros derechos igualmente esenciales de las personas ${ }^{35 "}$, y luego nos da ejemplos de esa protección que debe otorgarse cuando nos dicen “(....) derechos tales como el derecho al trabajo con una justa retribución, la intangibilidad del patrimonio y el derecho a emprender actividades empresariales no puede verse

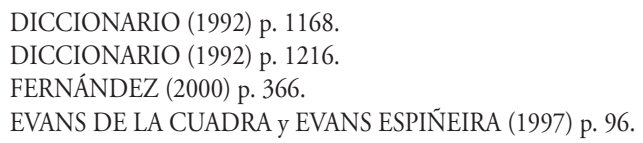


menoscabado con tributos excesivos que generen un atentado a los mismos derechos, lo que obviamente es contrario a la Constitución ${ }^{36 "}$.

Se debe tener presente que existirá siempre una vulneración de la justicia impositiva y como correlato necesario del principio de Igualdad Impositiva cuando se establezca un tributo confiscatorio. El efecto confiscatorio se presenta cuando los tributos son excesivos, o sea, cuando influyen sobre un porcentaje importante de la renta. Este efecto se puede lograr con un tributo en particular o con una suma de ellos. El excelentísimo Tribunal Constitucional ya tuvo ocasión de pronunciarse sobre estos aspectos ${ }^{37}$.

Finalmente debemos señalar que este elemento queda contenido en la protección del derecho de igualdad ante la ley, ello por cuanto dicho derecho se encuentra protegido por el inciso $1^{\circ}$ del número 20 del artículo 19, al establecer, la norma en comento, la igual repartición de los tributos y la igual repartición de las demás cargas públicas.

\section{2) La Proporcionalidad Impositiva.}

Puede entenderse como la progresión aritmética a la riqueza gravada. Esto es, que a mayor riqueza, mayor impuesto, de manera tal que la alícuota invariable o directamente proporcional al monto de la riqueza es la que realmente expresa un impuesto proporcional en el sentido constitucional.

De acuerdo a lo señalado en el Diccionario de la RAE, proporcionalidad debe entenderse como: "Conformidad o proporción de unas partes con el todo o de cosas relacionadas entre si" ${ }^{\prime 38}$. A su turno proporción es "Disposición, conformidad o correspondencia debida de las partes de una cosa con el todo o entre cosas relacionadas entre si"39. De este modo se dirá, en una primera aproximación, que el elemento de la proporcionalidad es aquel en virtud del cual la potestad tributaria establecerá los diversos tributos de conformidad o proporción de una de las partes con el todo, o de cosas relacionadas entre sí; lo que significa que la correspondencia debe existir entre los tributos que consagra un régimen jurídico con los elementos objetivos que lo conforman; se trata en general de que no se establezcan elementos irrazonables o sin fundamento en Derecho, en el establecimiento del tributo, de ahí que su relación con la justicia impositiva sea fundamental, y más tarde, con la igualdad impositiva, conformando un complejo estructural que debe ser respetado en todo momento por la autoridad al ejercer su potestad tributaria.

Cabe reiterar que este subprincipio encuentra referencia explícita en el texto del inciso $2^{\circ}$ del número 20 del artículo 19 de la Carta Fundamental.

La proporcionalidad es un elemento necesario para ciertos tributos en lo que hace real y efectiva la garantía de la igualdad tributaria, representa una de las bases más sólidas

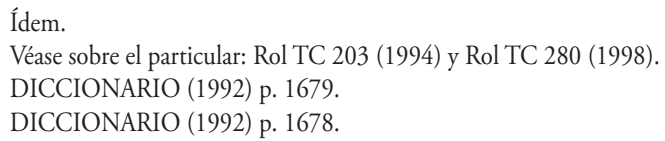


para lograr la equidad. Como garantía del derecho de propiedad significa que la carga tributaria sobre la riqueza debe ser adecuada y racional, o sea, que la presión que el tributo produce sobre la riqueza según la naturaleza de ésta y las características del tributo, guarden una cierta medida que para ser justa no exceda lo que aconseja una buena prudencia. La proporcionalidad no debe ser tomada exclusivamente como una progresión aritmética, sino que dentro de ese concepto cabe la proporción geométrica, es decir, la progresividad, sobre la cual nos referiremos más adelante.

En relación con este elemento, ya se ha señalado por la jurisprudencia que “(....) asegura la debida confianza de que el tributo o gabela que se imponga a los servicios, concesiones o permisos, que es la materia que ahora interesa, guarde la debida relación equitativa con tales servicios, concesiones o permisos, sobre la base de pautas permanentes e inequívocas, como una forma de respetar el principio básico de igualdad ante la ley e igual repartición de los tributos, tal como este último principio aparece concebido en el artículo 19 № 20, inciso $1^{\circ}$, manteniendo dentro de ciertos márgenes relativos el equilibrio necesario para tratar de que en situaciones iguales, las cargas o el sacrificio del tributario sean también semejantes" ${ }^{40}$ Se observa cómo la Corte Suprema lo entiende como una forma de respetar el principio de igualdad en la imposición de tributos.

La proporcionalidad del tributo está íntimamente ligada con elementos de carácter cuantitativo u objetivo que determinan el tributo como, por ejemplo, la base imponible, la capacidad contributiva de los sujetos afectos a tributos o la tasa que ha de aplicarse. Importa también este nexo con la circunstancia de que, al igual que la justicia impositiva, la proporcionalidad tributaria forma parte integrante de la igualdad, pero referida en especial a los tributos en un ámbito de mayor precisión conceptual.

Ayudándonos en nuestra tesis, se ha señalado que "la proporcionalidad y la progresividad, más que principios propiamente dichos, son técnicas mediante las cuales se satisface el principio de igualdad como principio inspirador del sistema tributario, al servicio de una efectiva igualdad de hecho" ${ }^{41}$. Esto confirma, por la más importante de las opiniones tributario-constitucionales, que la igualdad tributaria es el principio que envuelve a los elementos que la constituyen, mientras que sus elementos configuran un principio que garantice fuertemente el derecho de las personas, y no tan solo de los contribuyentes.

Debemos considerar que la desproporcionalidad, para constituirse como inconstitucional, debe ser manifiesta; sin embargo este criterio no puede constituir un parámetro único para determinar en qué circunstancias existe un tributo desproporcionado; en ese sentido compartimos lo señalado en orden a que "(....) el imperativo de advertir, categórica y nítidamente, que la prohibición del Poder Constituyente no se refiere solo a tributos manifiesta, evidente o descubiertamente desproporcionados o confiscatorios, sino que también a los que sean, con análogos rasgos de ostensible o patente, injustos,

\footnotetext{
Compañía de Teléfonos de Chile con Ilustre Municipalidad de Villa Alemana, Co 8 o (1992). SPISSO (2000) p. 336.
} 
inequitativos, irracionales, discriminatorios, improcedentes, inconducentes al objetivo buscado o, en general, ilegítimos por cualquiera otro motivo sustantivo ${ }^{42}$ ".

Ahora, no puede establecerse a priori en qué casos nos encontramos ante tributos desproporcionados, sino que debe analizarse una a una las circunstancias que determinan la contravención constitucional, según ha señalado Carlos Giuliani Fonrouge, “(....) la discreción o razonabilidad de los impuestos es materia circunstancial y de hecho, que debe apreciarse de acuerdo con exigencias de tiempo y lugar y conforme a finalidades económico-sociales de cada tributo ${ }^{43}$ ".

De esta forma, la vulneración del derecho debe verificarse desde una óptica indudablemente casuística ${ }^{44}$. En esta misma línea de pensamiento, cada vez que se produzca un acto atentatorio contra el principio en análisis, le corresponde probar dicha situación a quien la alega ${ }^{45}$.

\section{B) Elementos o Subprincipios Implícitos.}

\section{1) La Generalidad Impositiva.}

El primer elemento implícito, dentro de la estructura de la igualdad impositiva, que no se encuentra expresamente consagrado por la Carta Fundamental, impone una obligación jurídica general a todos los habitantes del país, a concurrir con el levantamiento, no tan solo de todos los tributos, sean impuestos, tasas o contribuciones especiales, sino que de todas las cargas públicas.

Como consecuencia directa de esta generalidad, no se puede eximir a nadie de su obligación impositiva, sino es por razones que no sean la carencia de capacidad contributiva, ya que la ordenación de los tributos ha de basarse en la capacidad económica de las personas llamadas a satisfacerlos y en la equitativa y proporcional distribución de la carga impositiva; todo esto constituye claramente un resguardo en los derechos de las personas, pues la generalidad en la imposición tributaria permite esta discriminación en el trato tributario.

CEA (1999) p. 135.

GIULIANI (2001) p. 266.

4 En otros ordenamientos, a diferencia de lo que ocurre en nuestro país, se ha prefigurado un parámetro, a partir del cual el tributo se considera desproporcionado, así en Argentina se ha seńalado que “(....) el derecho judicial (argentino) ha elaborado una pauta importante en orden a la confiscatoriedad, estableciendo que el gravamen que absorbe más del treinta y tres por ciento de la materia imponible (....) es inconstitucional por lesión del derecho de propiedad (....)”. Se agrega, además, que “(....) cuando la superposición o acumulación de varias contribuciones fiscales que soporta un mismo contribuyente excede el limite por encima del cual se considera inconstitucional un tributo (33\%), hay que admitir la viabilidad de la impugnación global a dicha carga en su conjunto, a causa de la confiscatoriedad que alberga la sumatoria de todos los tributos"; BIDART (1993) pp. $531-532$.

45 El artículo 1698 del Código Civil Chileno señala en su inciso 1º, que "Incumbe probar las obligaciones o su extinción al que alega aquéllas o esta”. 
Este elemento lo que prohíbe es la existencia de privilegios fiscales, porque en sentido técnico estricto, el tema se refiere más específicamente a las directrices que el legislador ordinario ha de seguir para la selección de los hechos imponibles, en acatamiento a la capacidad contributiva.

Ahora, y en la línea que planteábamos más arriba, el subprincipio de generalidad se une y forma parte de la igualdad tributaria en cuanto igualdad ante la ley y se ha señalado sobre este particular que, "el principio de generalidad de la imposición exige que, por una parte, todas las personas(naturales y jurídicas) -en tanto tengan capacidad de pago y queden tipificadas por alguna de las razones legales que dan nacimiento a la obligación tributaria, sin que se tengan en cuenta para ello criterios extraeconómicos, tales como nacionalidad, estamento y clases sociales, religión, raza, etc.- sean sometidas al gravamen tributario y que, por otra parte, no se admitan en el marco de un impuesto en particular otras excepciones a la obligación tributaria subjetiva y objetiva que las que parezcan inexcusables por razones de política económica, social, cultura, sanitarias o por imperativos de la técnica tributaria" ${ }^{\prime 6}$.

\section{2) La Capacidad Contributiva o Económica.}

Es un elemento de la razonabilidad, de innegable presencia en nuestro texto constitucional, aun cuando lo sea implícitamente, pues los tributos en caso alguno pueden afectar los derechos en su esencia, según lo asegura el número 26 del artículo 19 de la Constitución, que al igual que el elemento de la generalidad impositiva, es legitimador del establecimiento de los tributos y por su complejidad debe ser analizado en conjunción con la política, economía, sociología, ética y recaudación, esto en razón de que el contenido del principio confiere equidad y proporcionalidad, tanto así, que en algunos sistemas constituye un principio autónomo. Es además la garantía individual que permite alcanzar un equilibrio de la justicia social en la distribución de las cargas públicas.

La capacidad contributiva implica que solo aquellos hechos de la vida social que son índices de capacidad económica pueden ser adoptados por las leyes como hecho generador de la obligación tributaria. Mas la estructura del tributo y la medida en que cada uno contribuirá a los gastos públicos no está determinada solamente por la capacidad económica del sujeto pasivo, sino también por razones de conveniencia, justicia social y de bien común, ajenas a la capacidad económica; por lo demás, es de lógica deducción que no se tendrá capacidad económica si no se tiene lo mínimo para subsistir.

Ahora en este sentido, Spisso nos señala que "decir que todos deben contribuir no implica que no habrá excepciones, ya que la causa de la obligación de contribuir es la capacidad económica, y sin capacidad no existe constitucionalmente obligación de contribuir. Vemos, entonces, como generalidad y capacidad económica pueden ser vistas 
como especificaciones del principio de igualdad ${ }^{47}$, , o como elementos o subprincipios, según nuestro concepto, ya que ambos elementos, generalidad y capacidad económica, constituyen bases fundamentales sobre las cuales se estructura la igualdad, entendida ella como medida de la obligación tributaria.

Finalmente, confirmando nuestro planteamiento, se ha señalado que "el llamado principio de capacidad económica no es en sí mismo un verdadero principio de justicia tributaria, sino el presupuesto del que hay que partir para la elaboración de una serie de reglas que permiten llegar en la medida de lo posible a un justo reparto de los impuestos entre los ciudadanos ${ }^{48 ”}$.

\section{3) La Progresividad Impositiva.}

Tiene como fundamento la efectiva igualdad, al buscar que la carga tributaria se distribuya de manera proporcional y según la capacidad contributiva del sujeto pasivo, es decir, que exista una mejor distribución de su renta y patrimonio. Este elemento se relaciona íntimamente con la proporcionalidad. La progresividad está referida de modo directo al sistema tributario, al conjunto de tributos legalmente establecidos, y no de modo particular a cada uno de los tributos que lo conforman. Un impuesto es financieramente progresivo cuando la alícuota se eleva a medida que aumenta la cantidad gravada y proporcional cuando su alícuota es constante, cualquiera que sea la cantidad gravada.

Para que un sistema tributario tienda a la progresividad debe restaurarse el equilibrio, por ello hay que contrabalancear los impuestos indirectos con los directos, los primeros de carácter regresivo y los últimos progresivos.

En este marco, el concepto de capacidad contributiva no puede ser objeto de determinación exacta, dependiendo en gran parte de criterios filosófico-políticos dominantes en cada momento y en cada sociedad, cuya valoración depende en gran medida del poder discrecional de los parlamentos, lo cual igualmente no impide su cuestionamiento por el Poder Judicial en caso que dicho poder discrecional se torne en arbitrariedad. En concordancia se ha dicho que "igualdad formal" o "en la ley" no supone la exclusión de legislar para un determinado grupo de personas, sino que ello será admisible siempre que la categorización responda a criterios de razonabilidad por los cuales se respete a su vez un trato igualitario entre quienes compartan una misma categoría.

Es importante rescatar lo que la ciencia económica ha señalado, a propósito de la progresividad del tributo. La técnica del impuesto progresivo tiene una justificación ideológica explicada, a su vez, económicamente. La Teoría de la Utilidad Marginal ${ }^{49}$ nos dice que en la medida que aumenta la cantidad de un bien, disminuye en una progresión variable la satisfacción por su consumo. Así por ejemplo, en el impuesto a

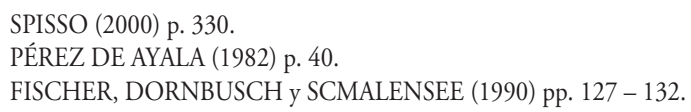


la renta, si aumenta el ingreso de una persona, disminuye la satisfacción en los últimos (marginales) incrementos de aquél, porque quedan menos de las necesidades principales de la persona por satisfacer (sin perjuicio de que la economía positiva dicta que las necesidades son ilimitadas). Esta teoría económica ha sido tomada para justificar la progresión del impuesto con una finalidad de redistribución de la riqueza que permita la igualdad de sacrificio de los contribuyentes. Mientras mayor ingreso, menor insatisfacción de necesidades, mayor razonabilidad para cobrar más impuesto.

Legalmente no hay un límite para la magnitud de las tasas de estos impuestos, pero sí hay un límite económico. La Curva de Laffer ${ }^{50}$ tiene especial relevancia en los impuestos progresivos. La progresividad solo puede prolongarse hasta un punto, pasado el cual, la recaudación disminuye, pues el contribuyente opta por dejar de desarrollar la actividad que determina este incremento -deja de producir-; esta observación empírica ha generado la formulación de la proposición de economía normativa más importante en esta materia, a la cual debe atender el legislador: la progresión tiene un límite.

\section{4) La No Confiscatoriedad Impositiva.}

La no confiscatoriedad protege al derecho de propiedad, garantía fundamental en un Estado democrático, lo que se deriva de la libertad, que es uno de los pilares que sirve de base al sistema democrático. De aquí se desprende la necesidad de evitar que el indispensable poder tributario se convierta en un arma de destrucción de la economía y de la sociedad, excediendo los límites más allá de los cuales los integrantes de un país no están dispuestos a tolerar su carga.

La no confiscatoriedad no se traduce en una antinomia entre el derecho de propiedad y el tributo, ya que éste constituye el precio que hay que pagar para vivir en sociedad, lo que exige soportar los gastos del Estado encargado de cumplir y hacer cumplir la Constitución; no obstante, debe existir un límite al poder de imposición, sin el cual el derecho de propiedad no tendría razón de ser.

Ese límite viene dado por el principio de no confiscatoriedad de los impuestos, que debe ser precisado clara y conceptualmente en el texto constitucional, de ahí que en nuestro sistema exista una necesidad de precisar este elemento en el ámbito constitucional, aun cuando debe siempre tenerse presente lo establecido en el artículo 19 número 24 del Código Político.

Existe confiscatoriedad tributaria cuando el Estado se apropia de los bienes de los contribuyentes, aplicando una norma tributaria en la que el monto llega a extremos insoportables por lo exagerado de su quantum o tasa impositiva, desbordando así la capacidad contributiva de la persona y vulnerando por esa vía indirecta la propiedad privada. De lo anterior se desprende que la no confiscatoriedad es un límite a la progresividad, y como quiera que esa progresividad atiende al sistema tributario, 
igualmente la no confiscatoriedad debe armonizarse dentro de ese sistema tributario constitucional, independientemente que el principio se refiera a un tributo específico, como igualmente debe satisfacer las directrices del bien común, al cual el Estado está llamado a propender ${ }^{51}$.

El exceso en el ejercicio del poder fiscal, puede ser considerado como una verdadera confiscación de bienes vedada por la Constitución, ya que debe existir la razonabilidad como medida de la confiscatoriedad de los gravámenes puesto que el poder impositivo ha de ser ejercido de buena fe y para fines públicos, debe establecerse con arreglo a un sistema de imparcialidad y uniformidad, en condiciones razonables y de manera tal que no constituya una confiscación.

La razonabilidad es un presupuesto indispensable en todo el orden jurídico, que se violenta cada vez que hay desproporción entre el fin perseguido por la norma y el medio elegido para concretarlo; un tributo sale de la razonabilidad cuando equivale

51 Ya señaló el Tribunal Constitucional en su sentencia Rol 280, considerando 8º, que: "sobre el particular debe recordarse que una petición similar ya fue resuelta por este Tribunal, en sentencia de 31 de julio de 1995, Rol No 219, que a propósito del impuesto al tabaco declaró "en materia de impuestos indirectos que gravan el consumo, el Tribunal se ha pronunciado claramente en cuanto a que '...la desproporcionalidad o injusticia de la tasa del tributo es difícil de determinar, pues existen múltiples factores, todos de hecho, que inciden en su calificación”". Mención expresa hace el Tribunal de estos factores: la capacidad de pago del contribuyente, la calificación del bien como de uso o consumo habitual o de carácter suntuario o prescindible o, si con su imposición se impide el desarrollo de una actividad económica (Considerando $8^{\circ}$ ). Complementando lo anterior, ha seńalado que en ningún caso el constituyente fijó un monto o rango para los gravámenes que afectan a las rentas, pero sí les fijó un límite. Este impide al legislador establecer desproporciones injustificables o irracionales. En la citada sentencia, este Tribunal reflexionó en su considerando 9º en torno a que “...no puede dejar de señalar que un impuesto indirecto podría, entre otras situaciones, ser manifiestamente desproporcionado o injusto si con su imposición o monto se impide del todo o se limita de tal manera que hace imposible el libre ejercicio de una actividad económica o impide la adquisición del dominio de los bienes a que afecte el impuesto". Sin embargo, para el Tribunal, el control de constitucionalidad de un tributo indirecto debe verificarse con relación a la ley objeto de controversia constitucional, esto es, con la que eleva sus tasas. No obstante que las razones son similares y comunicables, este Tribunal en esta oportunidad reflexiona nuevamente considerando que le corresponde fijar el sentido de la proporcionalidad y decidir que, sin perjuicio de sus atribuciones a futuro, el monto que se propone ahora, por el proyecto, en función del contexto de lo que se pide, no constituye una desproporcionalidad que lo deje fuera del límite constitucional”; más adelante el Tribunal Constitucional sostiene que, "19. (....) Por tanto, el Constituyente se guardó de restringir en exceso la autonomía del legislador, y le impuso un límite que solo impide las desproporciones o injusticias "manifiestas", esto es, aquellas que resultan burdas, exageradas e injustificables. Las restricciones al legislador en esta materia son, entonces, particularmente excepcionales. Ello implica que la defensa de la supremacía constitucional en este ámbito, ha de circunscribirse a evitar las desproporciones o injusticias tributarias que traspasen todos los límites de lo razonable y prudente. La desproporción o injusticia tiene que fluir de las propias preceptivas legales, cualesquiera sean los hechos que digan relación con las materias previstas en ellas. Dicho todavía de otra manera, la desproporción o injusticia tiene que ser tan evidente que, cualesquiera sean los hechos, ella resulte patente y clara en la propia disposición legal. Cabe tener presente que al no encontrarse contemplado por la Constitución o la ley un concepto de lo que se entiende por manifiestamente desproporcionado o injusto, tal determinación debe quedar entregada a lo que la justicia constitucional decida, caso a caso, en materia de proyectos de ley o de leyes. En nuestro país, tanto el Tribunal Constitucional como la Corte Suprema, dentro de sus respectivas competencias, se han pronunciado sobre el particular. En opinión del Presidente de la República la elección de los tributos específicos no ha sido, en modo alguno, caprichosa o carente de razón, sino que racionalmente justificada, y ha estado inspirada, ademas en el menor daño que su alza generará para la generalidad de la población. También debe tenerse en cuenta que este gravamen es trasladado al público consumidor y que, en la medida que éste siga adquiriendo los productos en que incide, no se produce, en principio, perjuicio a la empresa productora o distribuidora. Ello confirma la opinión de muchos autores en torno a que el artículo 19, № 20, de la Constitución, se refiere solo a impuestos directos (....)". 
a una parte substancial del valor del capital o de su renta o de su utilidad, o cuando ocasiona el aniquilamiento del derecho de propiedad en su sustancia o en cualquiera de sus atributos.

\section{Conclusiones.}

Después de analizar en estas páginas, el llamado por nosotros, Principio de Justa y Proporcional Igualdad Tributaria o Impositiva, corresponde dar a conocer las conclusiones que estas líneas nos presentan con claridad.

1. La justa y proporcional igualdad tributaria no es muy distinta, en sus fundamentos, a la igualdad general que ha establecido el constituyente del año 1980, en el artículo 19 No 2; sin embargo, aquella presenta elementos o subprincipios diferenciadores, que solo pueden interpretarse y explicarse integrados, ello con la finalidad de establecer un verdadero sistema de protección y garantías de los derechos de los contribuyentes. Estos elementos pueden agruparse en elementos de carácter explícito, como la justicia y la proporcionalidad, como asimismo, y de igual importancia, elementos de carácter implícito, como lo son la generalidad, la capacidad contributiva, la progresión y la no confiscatoriedad.

2. En nuestro sistema constitucional, solo puede hablarse de un verdadero principio de igualdad tributaria, a partir de su establecimiento en la Constitución de 1833, fijándose, este principio, en términos bastante básicos e integrando normas constitucionales que no solucionaban las dicotomías conceptuales siguientes: a) entre tributo, impuesto y contribuciones; b) entre facultades y haberes. Solo a partir de la Constitución de 1980 se resuelven, en parte, aquellos problemas, estableciéndose, en mi concepto, un Principio de Justa y Proporcional Igualdad Tributaria.

3. El principio constitucional de igualdad tributaria puede concebirse, en Chile, como un Principio de Justa y Proporcional Igualdad Tributaria, ello desde el momento que los elementos explícitos en el texto del inciso $2^{\circ}$ del artículo 19 de la Constitución, más que constituir principios autónomos, constituyen elementos o subprincipios que dan verdadera fisonomía a la igualdad tributaria, sea cuantitativamente o cualitativamente, y que unidos a los elementos implícitos, estructuran un verdadero sistema de resguardo a los derechos fundamentales de las personas.

4. Teniendo presente lo anterior, surge, como consecuencia directa del establecimiento del principio de justa y proporcional igualdad tributaria, y en plena armonía con el principio constitucional de igualdad ante la ley, fijado en el $n^{\circ} 2$ del artículo 19 de la Carta Fundamental, el derecho a no sufrir discriminaciones de ningún tipo en el tratamiento que los órganos del Estado deben dar a las personas en el ámbito tributario, a no ser tratados de manera diferente quienes se encuentren en una misma situación jurídica y económica. De ahí entonces, la necesidad o, 
más aún, la obligación para los órganos del Estado, de orden constitucional, para determinar específicamente si se encuentran las personas en situaciones idénticas o disímiles, todo ello con pleno respeto al Principio Constitucional de Legalidad Tributaria.

5. Aun cuando no se comparta la nomenclatura señalada en esta exposición, en torno a los elementos configuradores de la Igualdad Tributaria, lo que no debe ser objeto de discusión alguna es que la autoridad tributaria, en su función administradora, fiscalizadora, recaudadora, legislativa, judicial o contralora, no puede en caso alguno, so pena de nulidad y de responder por los perjuicios causados, vulnerar estos elementos en la imposición de los tributos o en la interpretación de las normas que constituyen el sustrato material en el que se desenvuelven los diversos actores tributarios, en resumen, pleno y absoluto respeto por los derechos de los contribuyentes, en especial, y de las personas, en general.

6. Pueden establecerse, con absoluto respeto del principio de justa y proporcional igualdad tributaria, establecido en el texto constitucional, posibilidades de distinción o de tratamientos tributarios desiguales, que no sean arbitrarios, y ello se puede producir, tomando los elementos que informan y estructuran el principio en comento, en los siguientes casos: a) Fijando tributos disímiles que miren o atiendan a la capacidad contributiva o económica de los contribuyentes; b) Estableciendo diferencias de tasas impositivas, según se trate de contribuyentes internos o externos; c) Configurando impuestos a sociedades cuyos capitales o direcciones se encuentren establecidos fuera del país; d) Regulando el valor de las patentes municipales, con valores o tasas diferenciadas, según la actividad que ellas graven; y e) Estableciendo sistemas de imposición diferenciados para zonas extremas del país y que requieren planes especiales de desarrollo, atendidas sus condiciones geográficas. Todo lo cual debe sujetarse a criterios y lineamientos técnicos razonables y objetivos.

7. Queda aún pendiente, una mejor sistematización de los Principios Constitucionales del Contribuyente, de parte de la Justicia Constitucional, sea la Corte Suprema, sea el Tribunal Constitucional, ello en vista de establecer un sistema de principios coherentes con los principios básicos del régimen constitucional chileno, garantizando los derechos de las personas, limitando los poderes de la autoridad Estatal, en cualquiera de sus ámbitos de actuación (legislativo, judicial, administrativo, contralor) y dando certeza y seguridad jurídica al siempre polémico tema de la tributación. 


\section{Bibliografía Citada}

ALDUNATE LIZANA, Eduardo (2008): Derechos Fundamentales (Santiago, Editorial Lexis - Nexis).

BENADAVA, Santiago (1993): Derecho Internacional Público (Santiago, Editorial Universitaria S.A.).

BIDART CAMPOS, José Germán (1993): Tratado Elemental de Derecho Constitucional (Buenos Aires, Ediciones Ediar) t. I.

CEA EGAÑA, José Luis (1999): El Sistema Constitucional de Chile: Sintesis Critica (Valdivia, Publicaciones Universidad Austral de Chile).

DICCIONARIO DE LA LENGUA ESPAÑOLA (1992): 21ª Edición (Madrid, Ediciones Espasa Calpe S.A.).

EVANS DE LA CUADRA, Enrique y EVANS DE LA CUADRA ESPIÑEIRA, Eugenio (1997): Los Tributos ante la Constitución (Santiago, Editorial Jurídica de Chile).

FERNÁNDEZ GONZÁLEZ, Miguel Ángel (2000): "Principios Constitucionales de Proporcionalidad y Justicia en Materia Tributaria", Revista Chilena de Derecho Pontificia Universidad Católica de Chile, V. 27.

FERRAJOLI, Luigi (2006): Derechos y Garantías: La Ley del más Débil (Madrid, Editorial Trotta).

FIGUEROA VALDÉS, Juan Eduardo (1985): Las Garantías Constitucionales del Contribuyente en la Constitución de 1980 (Santiago, Editorial Jurídica de Chile).

FISCHER, Stanley; DORNBUSCH, Rudiger y SCHMALENSEE, Richard (1990): Economía (Santiago - Madrid, Editorial Mc Graw Hill).

GIULIANI FONROUGE, Carlos (2001): Derecho Financiero (Buenos Aires, Editorial Depalma).

JARACH, Dino (1980): Curso Superior de Derecho Tributario (Buenos Aires, Ediciones Cima) t. I.

MASBERNAT MUÑOZ, Patricio (2002): "Garantías Constitucionales del Contribuyente: Crítica al Enfoque de la Doctrina Nacional”; Revista Ius et Praxis, Universidad de Talca, V. 8, No 2.

MEZA ENCINA, Bárbara e IBACETA MEDINA, David (2004): "Legalidad en la Imposición de Tributos. Una Mirada Constitucional”; Revista de Derecho Público, V. 66.

MEZA ENCINA, Bárbara e IBACETA MEDINA, David (2007): El Principio Constitucional de Legalidad en Materia Tributaria (Santiago, Editorial Lexis Nexis).

NEUMARK, Fritz (1989): Principios de la Imposición (Madrid, Instituto de Estudios Fiscales). 
PÉREZ DE AYALA, José Luis (1982): “Comentario al artículo 3 o de la Ley General Tributaria”; Comentarios a las Leyes Tributarias y Financieras (Madrid, Editoriales de Derecho Reunidas) t. I.

PÉREZ ROYO, Fernando (1985): "Principio de Legalidad, Deber de Contribuir y Decretos-Leyes en Materia Tributaria”; Revista Española de Derecho Constitucional, $\mathrm{N}^{\circ} 13$.

ROLDÁN, Alcibíades (1913): Elementos de Derecho Constitucional de Chile (Santiago, Imprenta, Litografía i Encuadernación Barcelona).

ROSEN, Harvey (2002): Hacienda Pública (Madrid, Ediciones M Graw Hill).

SILVA BASCUÑÁN, Alejandro (1963): Tratado de Derecho Constitucional (Santiago, Editorial Jurídica de Chile) t. III.

SPISSO, Rodolfo (2000): Derecho Constitucional Tributario, 2a Edición (Buenos Aires, Ediciones Depalma).

VALDÉS COSTA, Ramón (1996): Instituciones de Derecho Tributario (Buenos Aires, Ediciones Depalma).

VALENCIA AVARIA, Luis (1986): Anales de la República, 2a Edición (Santiago, Editorial Jurídica de Chile).

\section{Normativa Citada}

Auto Acordado de la Corte Suprema de Chile, de 24 de junio de 1992, sobre tramitación del Recurso de Protección de Garantías Constitucionales

Constitución Política de la República de Chile.

\section{Jurisprudencia Citada}

Telefónica de España S.A. (1993): Corte Suprema 19 abril 1993 (Recursos de queja, de protección y de inaplicabilidad por inconstitucionalidad), Revista de Derecho y Jurisprudencia y Gaceta de los Tribunales (Santiago, Editorial Jurídica de Chile), t. XC, No 1, S. 6a.

Requerimiento de inaplicabilidad por inconstitucionalidad de catorce Compañías de Seguros Generales respecto de los artículos $3^{\circ}$ y $4^{\circ}$ del Decreto Ley $N^{\circ} 1.757$, de 1977 Rol 1295 (2009): Tribunal Constitucional 06 octubre 2009 (Requerimiento artículo 93 No 6 Constitución Política), www.tribunalconstitucional.cl (Fecha de consulta: 26 agosto 2010).

Requerimiento de inaplicabilidad por inconstitucionalidad de Estadio Croata S.A. respecto del artículo $2^{\circ}$ de la Ley $\mathrm{N}^{\circ} 17.235$, sobre impuesto territorial Rol 1234 (2009): Tribunal Constitucional 07 julio 2009 (Requerimiento artículo 93 No 6 Constitución Política), www.tribunalconstitucional.cl (Fecha de consulta: 26 agosto 2010). 
Requerimiento de inaplicabilidad por inconstitucionalidad de Estadio Español S.A. respecto de los artículos $1^{\circ}, 3^{\circ}, 4^{\circ}, 5^{\circ}, 7^{\circ}, 10,12$ y 16 de la Ley $N^{\circ} 17.235$, y del artículo $2^{\circ}$ de la Ley $\mathrm{N}^{\circ} 20.033$ Rol 773 (2007): Tribunal Constitucional 26 noviembre 2007 (Requerimiento artículo 93 № 6 Constitución Política), www. tribunalconstitucional.cl (Fecha de consulta: 26 agosto 2010).

Requerimiento de inaplicabilidad presentado por Marta Álvarez de la Rivera Schmidt, respecto de los artículos $1^{\circ}, 3^{\circ}, 4^{\circ}, \mathrm{N}^{\circ} 2$ de la Ley $\mathrm{N}^{\circ} 17.235$ Rol 822 (2007): Tribunal Constitucional 13 noviembre 2007 (Requerimiento artículo 93 No 6 Constitución Política), www.tribunalconstitucional.cl (Fecha de consulta: 26 agosto 2010).

Requerimiento de inaplicabilidad presentado por Sociedad Anónima de Deportes Manquehue respecto de los artículos $1^{\circ}, 3^{\circ}, 4^{\circ}, 5^{\circ}, 7^{\circ}, 10,12$ y 16 de la Ley $\mathrm{N}^{\circ}$ 17.235, y del artículo $2^{\circ}$ de la Ley $\mathrm{N}^{\circ} 20.033$ Rol 759 (2007): Tribunal Constitucional 26 noviembre 2007 (Requerimiento artículo 93 № 6 Constitución Política), www.tribunalconstitucional.cl (Fecha de consulta: 26 agosto 2010).

Requerimiento de inaplicabilidad presentado por Sociedad de Deportes Palestina S.A. respecto de los artículos $1^{\circ}, 3^{\circ}, 4^{\circ}, 5^{\circ}, 7^{\circ}, 10,12$ y 16 de la Ley $\mathrm{N}^{\circ} 17.235$, y del artículo $2^{\circ}$ de la Ley $\mathrm{N}^{\circ} 20.033$ Rol 718 (2007): Tribunal Constitucional 26 noviembre 2007 (Requerimiento artículo 93 № 6 Constitución Política), www. tribunalconstitucional.cl (Fecha de consulta: 26 agosto 2010).

Requerimiento formulado por diversos Diputados con el objeto de que el Tribunal declare la inconstitucionalidad del Estatuto de Roma de la Corte Penal Internacional Rol 346 (2002): Tribunal Constitucional 08 abril 2002 (Requerimiento artículo 82 No 2 Constitución Política antes de la Ley de Reforma Constitucional $\mathrm{N}^{\circ}$ 20.050), www.tribunalconstitucional.cl (Fecha de consulta: 26 agosto 2010).

Requerimiento formulado por Senadores respecto del artículo $2 \mathrm{~N}^{\circ} 10$, letra a) del proyecto que modifica el Decreto Ley $\mathrm{N}^{\circ} 3.063$, de 1979, sobre rentas municipales Rol 203 (1994): Tribunal Constitucional 06 diciembre 1994 (Requerimiento artículo 82 No 2 Constitución Política antes de la Ley de Reforma Constitucional $\mathrm{N}^{\circ}$ 20.050), www.tribunalconstitucional.cl (Fecha de consulta: 26 agosto 2010). 